\title{
Inference of a causal relation between low- density lipoprotein cholesterol and hypertension using mendelian randomization analysis
}

Tae-Hwa Go ${ }^{1,2 \dagger}$, Kyeong Im Kwak ${ }^{3 \dagger}$, Ji-Yun Jang ${ }^{1,2}$, Minheui Yu ${ }^{4}$, Hye Sim Kim ${ }^{5}$ Jang Young Kim ${ }^{6}$, Sang Baek Koh ${ }^{7,8}$ and Dae Ryong Kang ${ }^{1,9^{*}}$ (D)

\begin{abstract}
Background: It is known in some studies that higher the $L D L-C$, the greater the risk of developing cardiovascular disease. However, studies of the causal effects between LDL-C and hypertension are limited by their observational study design, and genetic epidemiology studies of associations between LDL-C and hypertension are lacking, as are studies using data for Koreans. In this study, we confirmed the causal effect of LDL-C on hypertension using Korean chip data.

Method: The epidemiology and genotype data were collected from the Korean Genome and Epidemiology Study conducted by the Korea National Institute of Health and covered 20,701 subjects. Single-nucleotide polymorphisms associated with LDL-C were selected $\left(p\right.$-value $\left.<5 \times 10^{-8}\right)$ from the Global Lipids Genetics Consortium database, and Mendelian randomization analysis (MRA) was performed with counted genetic risk scores and weighted genetic risk scores (WGRSs) for 24 single-nucleotide polymorphisms.

Result: The assumptions for MRA were statistically confirmed, and WGRSs showed a strong association with LDL-C. Interestingly, while the relationship between LDL-C and hypertension was not statistically significant in the observational study, MRA study demonstrated that the risk of hypertension increased as LDL-C increased in both men and women.

Conclusions: The results of this study confirmed that the relationship between LDL-C and hypertension is greatly influenced by genetic information.
\end{abstract}

Keywords: Low-density lipoprotein cholesterol, Hypertension, Mendelian randomization, Genetic epidemiology

\footnotetext{
* Correspondence: dr.kang@yonsei.ac.kr

${ }^{\dagger}$ Tae-Hwa Go and Kyeong Im Kwak contributed equally to this work.

${ }^{1}$ Center of Biomedical Data Science, Yonsei University Wonju College of Medicine, Wonju, Republic of Korea

${ }^{9}$ Department of Precision Medicine, Yonsei University Wonju College of Medicine, 20 Ilsan-ro, Wonju-si, Gangwon-do 26426 Wonju, Republic of Korea Full list of author information is available at the end of the article
}

(C) The Author(s). 2021 Open Access This article is licensed under a Creative Commons Attribution 4.0 International License, which permits use, sharing, adaptation, distribution and reproduction in any medium or format, as long as you give appropriate credit to the original author(s) and the source, provide a link to the Creative Commons licence, and indicate if changes were made. The images or other third party material in this article are included in the article's Creative Commons licence, unless indicated otherwise in a credit line to the material. If material is not included in the article's Creative Commons licence and your intended use is not permitted by statutory regulation or exceeds the permitted use, you will need to obtain permission directly from the copyright holder. To view a copy of this licence, visit http://creativecommons.org/licenses/by/4.0/ The Creative Commons Public Domain Dedication waiver (http://creativecommons.org/publicdomain/zero/1.0/) applies to the data made available in this article, unless otherwise stated in a credit line to the data. 


\section{Background}

Hypertension, the most common cardiovascular disease in older adults, is one of the most important risk factors for cardiovascular diseases, including myocardial infarction, stroke, congestive heart failure, terminal renal disease, and peripheral vascular disease [1]. According to the World Health Organization, about 17 million people worldwide die from cardiovascular diseases, and about 9.4 million people die from hypertension. The prevalence of hypertension is expected to increase from $26 \%$ in 2000 to $29.2 \%$ in 2025, about 29\% worldwide. About half of all older adults in Korea are estimated to have hypertension [2, $3]$, increasing medical expenses in older adults and negatively affecting the quality of life of both the patient and their family $[4,5]$. As prevention of hypertension can alleviate the overall disease burden on society and improve quality of life, further research into hypertension prevention is needed, and since hypertension, a chronic disease, affects a number of factors, causal inference study of disease occurrence should incorporate genetic factors in addition to environmental factors [6].

In accordance with Mendel's second law, genetic factors can indirectly affect disease incidence through various risk factors, making it necessary to identify causal associations through Mendelian randomization analysis (MRA). Mendelian randomization reflects the natural, random assortment of genetic variants during meiosis, yielding a random distribution of genetic variants in a population [7], and has been used in epidemiologic studies to identify causal relationships between risk factors and outcomes when causal confounding or reverse causality may interfere with causality inference [7-10]. To determine the genetic basis of a phenotype or to characterize gene function, conventional studies in genetic epidemiology seek to document associations between genetic and phenotype variations within a population. In such studies, genetic variations are assessed using markers, often single nucleotide polymorphisms (SNPs), and markers are considered informative if they show sufficient variation within a population and are of high enough prevalence to allow for meaningful comparisons. Meanwhile, it is also possible to exploit the random assignment of genes as a means of reducing confounding when examining exposure-disease associations: this is Mendelian randomization in the epidemiological context [7].

It is known in some studies that higher the LDL-C, the greater the risk of developing cardiovascular disease. Also, intervention trials using statins to lower LDL cholesterol have consistently reported substantial reductions in major cardiovascular events in treated groups. However, these results were gleaned from epidemiological studies that did not include genetic factors [11-17]. Moreover, very few studies have been conducted in Asians.

Thus, in this study, we performed Mendelian randomization using Korean chip data to investigate the existence of causal effects between LDL-C and hypertension.

\section{Method \\ Study population}

This study evaluated participants included in a ruralbased, cardiovascular disease association study (CAVA S) among individuals of the Korean Genome Epidemiology Study (KoGES) conducted by the Korea Centers for Disease Control and Prevention. The CAVAS study covered the years 2005-2011 and recruited men and women aged 40-69 years living in 11 rural areas. A total of 28,338 people were recruited. Among them, 20,701 were surveyed for both epidemiological and genomic data. In this study, individuals who lacked information on systolic blood pressure (SBP), diastolic blood pressure (DBP), or LDL-C $(n=49)$ and those with triglycerides levels greater than $400 \mathrm{mg} / \mathrm{dL}$ were excluded $(n=472)$ [18]. Except for 644 subjects currently undergoing treatment for hyperlipidemia, a total of 19,536 subjects were analyzed in this study (Fig. 1). The study protocol was approved by the Institutional Review Board of Wonju Severance Christian Hospital (CR317334).

\section{Data collection}

Study participants were asked to complete selfreported questionnaires in order to assess their personal and family medical histories, smoking habits, alcohol consumption, exercise status, and use of medication. Smoking status and drinking status were categorized as never, past, or current. Height, body weight, and waist circumference were measured using standard methods. Waist circumference was measured at the narrowest point between the upper iliac crest and the lowest rib after normal expiration. Blood pressure was measured by averaging three recordings taken in the morning after at least 10 min of rest in a sitting position. Laboratory samples were obtained after a 12-h fast. Plasma total cholesterol, triglycerides, high-density lipoprotein cholesterol (HDL-C), creatinine, and alanine and aspartate aminotransferase levels were measured using a Hitachi 747 chemistry analyzer (Hitachi Ltd., Tokyo, Japan). LDL-C was assessed using the Friedewald equation. Nutrition was examined using data extracted from the Korea Health and Nutrition Examination Survey on multi-frequency foods in 1988 considering the contributions of each of the 17 major nutrients. 


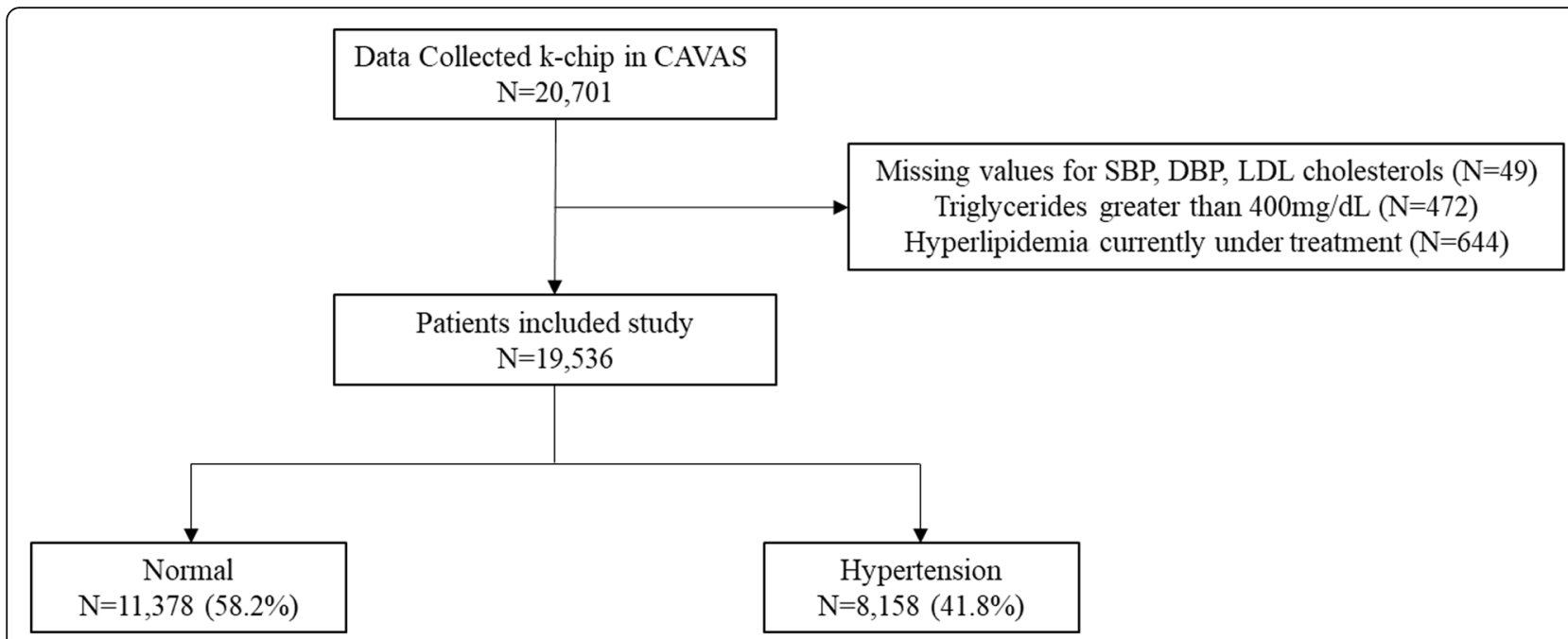

Fig. 1 Flow chart of the study. CAVAS, Cardiovascular Disease Association Study, SBP systolic blood pressure, DBP diastolic blood pressure, LDL-C low-density lipoprotein cholesterol

\section{Gene data source}

Genetic data were gleaned from next-generation sequencing and SNP information contained in K-CHIP (Center for Genetic Studies, Genome Center, Korea National Institute for Disease Control and Prevention). The K-CHIP comprises 830,000 representative SNPs in the Korean genome extracted from nextgeneration sequencing of more than 2000 Asian genomes and 1000 Korean genomes. Currently, K-CHIP covers about $95 \%$ of SNPs, with a genome representation of $5 \%$ or more [19].

\section{Hypertension and LDL-C}

Hypertension was defined in accordance with the Korean Society of Hypertension 2018 treatment guidelines [20]: 1) $\mathrm{SBP} \geq 140 \mathrm{mmHg}$, 2) $\mathrm{DBP} \geq 90 \mathrm{mmHg}$, or 3) currently undergoing treatment for hypertension. LDL-C was categorized as optimal (<100 mmHg), near optimal (100-219 $\mathrm{mmHg}$ ), borderline high (130-159 mmHg), high (160$189 \mathrm{mmHg}$ ), and very high ( $\geq 190 \mathrm{mmHg}$ ) as indicated by the National Cholesterol Education Program Adult Treatment Panel III. In the present study, LDL-C was analyzed as optimal $(<100 \mathrm{mmHg})$, near optimal $(100-219 \mathrm{mmHg})$, and high $(\geq 130 \mathrm{mmHg})$.

\section{Gene selection (genotype)}

Genes related to LDL-C was selected with reference to the Global Lipids Genetics Consortium (GLGC). Based on genome-wide association study results, we selected genes with $p$-values $<5 \times 10^{-8}$ for association between SNPs and LDL-C and with low linkage disequilibrium.
Of these, haplotypes were excluded. In total, 24 SNPs were selected for analysis.

\section{Statistical analysis}

To analyze differences in the general characteristics of the study subjects according to the presence of hypertension, t-test was used for continuous variables, and chi-square test was used for categorical variables.

Three analytical methods were used to confirm the relationship between LDL cholesterol and hypertension. In the first method, logistic regression analysis was performed to confirm relationships noted in observational study analysis. The second and third methods implemented Mendelian randomization for two-stage least square regression using counted genetic risk scores and weighted genetic risk scores, respectively. In total, three models were developed: model 1 was unadjusted; model 2 was adjusted for age, family history of hypertension, and body mass index; and model 3 was adjusted for the same covariates in model 2 in addition to smoking status, drinking status, and salt intake.

Before implementing MRA, three basic assumptions were proposed: Assumption 1 assumed that the instrumental variable would be associated with the exposure of interest. Assumption 2 assumed that the instrumental variable is dependent on factors confounding the association between exposure and the outcome. Assumption 3 assumed that the instrumental variable is only associated with the outcome through the exposure. 
Assumption 1 was confirmed through F-statistics and indicated that SNPs identified by consortium were associated with LDL-C. Only SNPs with $p$-values $<5 \times 10^{-8}$ were considered for analysis and confirmed LDL-C according to genotype through Cuzick's test. In addition, genetic risk scores (GRSs) were calculated for the SNPs satisfying the assumption, and linear relationships for counted GRSs and weighted GRSs with LDL-C were confirmed. Assumption 2 indirectly confirmed that the two relationships were independent by identifying differences from confounding factors according to genotypes of each SNP because direct proof was impossible. Finally, assumption 3 was confirmed using the DurbinWu-Hausman test and Sargan test.

All analyses were conducted using SAS version 9.4 (SAS Institute Inc., Cary, NC, USA), R version 3.3.1. and STATA. $p$-values $<0.05$ were considered indicative of statistical significance.

\section{Results}

Baseline characteristics

For the 19,536 subjects included in this study (men: 7253; women: 12,283), hypertension was recorded in 8158 (41.8\%). Compared with normal individuals, those with hypertension were older and had higher weight and waist circumference values. The mean $\pm \mathrm{SD}$ values of LDL-C were $124.5 \pm 31.5$ and $125.8 \pm 33.7 \mathrm{mg} / \mathrm{dL}$ in normal individuals and those with hypertension, respectively (Table 1).

\section{Association between genetic risk and LDL-C}

The 24 genes chosen through the GLGC are listed in Table 2. $p$-value $<5 \times 10^{-8}$ was used to confirm the statistical significance of the relationship between individual genes and LDL-C (Assumption 1). F-statistics values for the relationship between genetic risk and LDL-C in relation to counted and weighted GRSs were 262.9 and

Table 1 Baseline characteristics according to hypertension

\begin{tabular}{|c|c|c|c|}
\hline Variables & $\begin{array}{l}\text { Normal } \\
(N=11,378)\end{array}$ & $\begin{array}{l}\text { Hypertension } \\
(N=8158)\end{array}$ & $p$-value \\
\hline Sex & & & $<.0001$ \\
\hline Men & 4077 (35.8) & $3176(38.9)$ & \\
\hline Women & $7301(61.2)$ & $4982(61.1)$ & \\
\hline Age & $57.2 \pm 9.7$ & $60.9 \pm 9.0$ & $<.0001$ \\
\hline Family history of hypertension & $1937(17.2)$ & $2104(26.1)$ & $<.0001$ \\
\hline Smoking status & & & $<.0001$ \\
\hline Never smoker & $6367(71.0)$ & $4667(70.9)$ & \\
\hline Ex-smoker & 1219 (13.6) & $1059(16.1)$ & \\
\hline Current smoker & $1386(15.4)$ & $853(13.0)$ & \\
\hline Alcohol drinking & & & 0.0002 \\
\hline Never drinking & $6069(53.5)$ & $4113(50.5)$ & \\
\hline Ex-drinking & $782(6.9)$ & $628(7.7)$ & \\
\hline Current drinking & $4500(39.6)$ & $3400(41.8)$ & \\
\hline Exercise & & & $<.0001$ \\
\hline$<3$ times per weeks & $878(23.3)$ & $514(18.8)$ & \\
\hline$\geq 3$ times per weeks & $2888(76.7)$ & $2214(81.2)$ & \\
\hline Systolic blood pressure (mmHg) & $116.2 \pm 11.7$ & $138.3 \pm 17.0$ & $<.0001$ \\
\hline Diastolic blood pressure $(\mathrm{mmHg})$ & $73.9 \pm 8.0$ & $85.8 \pm 11.0$ & $<.0001$ \\
\hline Body mass index $\left(\mathrm{kg} / \mathrm{m}^{2}\right)$ & $23.9 \pm 3.0$ & $25.1 \pm 3.2$ & $<.0001$ \\
\hline Waist circumference $(\mathrm{cm})$ & $82.5 \pm 8.6$ & $85.9 \pm 8.7$ & $<.0001$ \\
\hline $\mathrm{HDL}-\mathrm{C}(\mathrm{mg} / \mathrm{dL})$ & $45.7 \pm 11.1$ & $45.0 \pm 11.1$ & $<.0001$ \\
\hline LDL-C (mg/dL) & $124.5 \pm 31.5$ & $125.8 \pm 33.7$ & 0.0072 \\
\hline Total cholesterol (mg/dL) & $195.8 \pm 35.1$ & $200.6 \pm 36.8$ & $<.0001$ \\
\hline Triglyceride (mg/dL) & $128.0 \pm 64.9$ & $148.9 \pm 72.4$ & $<.0001$ \\
\hline Salt intake (mg) & $2530.4 \pm 1544.6$ & $2470.1 \pm 1517.2$ & $<.0001$ \\
\hline
\end{tabular}

Values are presented as a number (percentage) or mean \pm standard deviation

SBP Systolic blood pressure, DBP Diastolic blood pressure, BMI Body mass index, HDL-C High-density lipoprotein cholesterol, $L D L-C$ Low-density lipoprotein cholesterol 
Table 2 List of 24 SNPs included to calculate genetic risk score for LDL-C

\begin{tabular}{|c|c|c|c|c|c|c|c|}
\hline Chromosome & SNP & Gene & Risk allele & Other allele & $\beta$ & $\mathrm{SE}(\beta)$ & F-statistic \\
\hline 1 & rs41279716 & CELSR2 & A & $\mathrm{T}$ & 0.0518 & 0.0065 & 20.27 \\
\hline 1 & rs4970834 & CELSR2 & $C$ & T & 0.1503 & 0.0047 & 33.26 \\
\hline 1 & rs79868705 & CELSR2 & G & A & 0.0851 & 0.0126 & 10.47 \\
\hline 1 & rs79482788 & CELSR2 & G & A & 0.0864 & 0.0126 & 10.49 \\
\hline 1 & rs12740374 & CELSR2 & G & T & 0.1610 & 0.0044 & 44.21 \\
\hline 1 & rs35358959 & PSRC1 & G & $A$ & 0.0986 & 0.0088 & 18.94 \\
\hline 1 & rs672569 & PSRC1 & G & $A$ & 0.1431 & 0.0082 & 19.47 \\
\hline 1 & rs11596737 & PDLIM1 & G & A & 0.0968 & 0.0088 & 20.86 \\
\hline 1 & rs17645031 & MYBPHL & $C$ & T & 0.1004 & 0.0067 & 17.49 \\
\hline 1 & rs41306199 & MYBPHL & C & T & 0.0903 & 0.0091 & 17.49 \\
\hline 11 & rs651821 & APOA5 & $C$ & T & 0.0722 & 0.0094 & 10.94 \\
\hline 11 & rs7952602 & ST3GAL4 & C & G & 0.0496 & 0.0054 & 10.67 \\
\hline 16 & rs8062041 & TXNL4B & $\mathrm{T}$ & $C$ & 0.0250 & 0.0038 & 17.01 \\
\hline 19 & rs2738452 & LDLR & G & A & 0.0624 & 0.0053 & 19.06 \\
\hline 19 & rs2738464 & LDLR & $C$ & G & 0.0422 & 0.0061 & 73.71 \\
\hline 19 & rs892114 & SPC24 & A & G & 0.0353 & 0.0047 & 14.01 \\
\hline 19 & rs6511727 & DOCK6 & $\mathrm{T}$ & G & 0.0266 & 0.0038 & 11.56 \\
\hline 19 & rs387976 & NECTIN2 & A & $C$ & 0.0818 & 0.0057 & 33.17 \\
\hline 19 & rs3852861 & NECTIN2 & G & T & 0.0347 & 0.0041 & 17.18 \\
\hline 19 & rs7254892 & NECTIN2 & G & $A$ & 0.4853 & 0.0119 & 241.13 \\
\hline 19 & rs7412 & APOE & $C$ & T & 0.5898 & 0.0101 & 307.79 \\
\hline 19 & rs445925 & APOC1 & G & A & 0.3634 & 0.0081 & 206.40 \\
\hline 19 & rs56131196 & APOC1 & A & G & 0.2011 & 0.0076 & 27.28 \\
\hline 19 & rs7259004 & APOC1P1 & G & C & 0.2094 & 0.0092 & 30.97 \\
\hline
\end{tabular}

LDL-C Low-density lipoprotein cholesterol, SNP Single-nucleotide polymorphism, SE Standard error

661.5 , respectively, which is much higher than the standard F-statistics of 10. In both men (counted GRS: 74.7; weighted GRS: 161.6) and women (counted GRS: 152.4; weighted GRS: 384.0), the relationship between the genes and LDL-C was strong (Table 3 ). In addition, the association between gene polymorphism and LDL-C was examined (Supplement Table 1).

Next, we examined differences in risk factors of hypertension according to APOE polymorphism (rs7412), which has the highest beta value in the GLGC (Assumption 2). In doing so, we noted statistically significant differences in LDL-C, HDL-C, total cholesterol, and triglyceride with $A P O E$ polymorphism (rs7412) (Table 4). In addition, we confirmed a trend of increasing LDL-C with increasing counted GRS (Fig. 2).

\section{Observational and Mendelian randomization analysis}

In observational analysis, the risk of hypertension according to LDL-C was not statistically significant in Model 3, which was adjusted for confounding variables in men and women. In MRA using counted GRS, the risk of hypertension was statistically significant as LDL-

Table 3 F-statistic and p-values for counted and weighted genetic risk scores

\begin{tabular}{|c|c|c|c|c|c|c|}
\hline \multirow[t]{2}{*}{ Genetic risk score } & \multicolumn{3}{|c|}{ Counted GRS } & \multicolumn{3}{|c|}{ Weighted GRS } \\
\hline & F-statistic & R-square & $p$-value & F-statistic & R-square & $p$-value \\
\hline All patients & 262.9 & 0.013 & $<2.2 \mathrm{e}-16$ & 661.5 & 0.033 & $<2.2 \mathrm{e}-16$ \\
\hline Men & 74.7 & 0.129 & $<2.2 \mathrm{e}-16$ & 161.6 & 0.028 & $<2.2 \mathrm{e}-16$ \\
\hline Women & 152.4 & 0.016 & $<2.2 \mathrm{e}-16$ & 384.0 & 0.039 & $<2.2 \mathrm{e}-16$ \\
\hline
\end{tabular}

GRS Genetic risk score 
Table 4 Association between APOE (rs7412) genotype and potential confounders

\begin{tabular}{|c|c|c|c|c|}
\hline Variables & $\begin{array}{l}\text { Wild type } \\
(N=17,153)\end{array}$ & $\begin{array}{l}\text { Heterozygous } \\
(N=2316)\end{array}$ & $\begin{array}{l}\text { Homozygous } \\
(N=67)\end{array}$ & $p$-value \\
\hline \multicolumn{5}{|l|}{ Sex } \\
\hline Men & $6373(37.2)$ & $853(86.8)$ & $27(40.3)$ & 0.8265 \\
\hline Women & $10,780(62.8)$ & $1463(63.2)$ & $40(59.7)$ & \\
\hline Age & $58.8 \pm 9.6$ & $58.6 \pm 9.4$ & $57.4 \pm 10.3$ & 0.4425 \\
\hline Family history of hypertension & $3557(20.9)$ & $473(20.6)$ & $11(16.4)$ & 0.6169 \\
\hline Smoking status & & & & 0.7190 \\
\hline Never smoker & $9695(70.9)$ & $1300(71.6)$ & $39(66.1)$ & \\
\hline Ex-smoker & $2011(14.7)$ & $259(14.3)$ & $8(13.6)$ & \\
\hline Current smoker & $1970(14.4)$ & $257(14.2)$ & $12(20.3)$ & \\
\hline Alcohol Drinking & & & & 0.8591 \\
\hline Never drinking & $8923(52.1)$ & $1224(52.9)$ & $35(52.2)$ & \\
\hline Ex-drinking & $1247(7.3)$ & $157(6.8)$ & $6(9.0)$ & \\
\hline Current drinking & $6943(40.6)$ & $931(40.3)$ & $26(38.8)$ & \\
\hline Exercise & & & & 0.7963 \\
\hline$<3$ times per weeks & $1231(21.6)$ & $156(20.6)$ & $5(19.2)$ & \\
\hline$\geq 3$ times per weeks & 4479 (78.4) & $602(79.4)$ & $21(80.8)$ & \\
\hline Systolic blood pressure (mmHg) & $125.6 \pm 17.9$ & $124.7 \pm 17.5$ & $124.2 \pm 17.8$ & 0.0912 \\
\hline Diastolic blood pressure $(\mathrm{mmHg})$ & $78.9 \pm 11.1$ & $78.6 \pm 10.9$ & $78.7 \pm 10.1$ & 0.5107 \\
\hline Body mass index $\left(\mathrm{kg} / \mathrm{m}^{2}\right)$ & $24.4 \pm 3.2$ & $24.4 \pm 3.2$ & $24.0 \pm 2.8$ & 0.6311 \\
\hline Waist circumference $(\mathrm{cm})$ & $83.9 \pm 8.8$ & $84.0 \pm 8.9$ & $82.8 \pm 8.7$ & 0.5142 \\
\hline $\mathrm{HDL}-\mathrm{C}(\mathrm{mg} / \mathrm{dL})$ & $45.2 \pm 10.9$ & $46.4 \pm 12.2$ & $46.3 \pm 12.2$ & $<.0001$ \\
\hline LDL-C (mg/dL) & $127.2 \pm 32.3$ & $110.2 \pm 28.9$ & $99.2 \pm 44.8$ & $<.0001$ \\
\hline Total cholesterol (mg/dL) & $199.6 \pm 35.7$ & $184.9 \pm 33.2$ & $176.4 \pm 56.0$ & $<.0001$ \\
\hline Triglyceride (mg/dL) & $136.1 \pm 68.4$ & $141.4 \pm 72.0$ & $154.8 \pm 82.1$ & 0.0002 \\
\hline Salt intake (mg) & $2507.4 \pm 1541.7$ & $2499.0 \pm 1482.4$ & $2167.4 \pm 1075.6$ & 0.1897 \\
\hline
\end{tabular}

Values are presented as a number (percentage) or mean \pm standard deviation

SBP Systolic blood pressure, DBP Diastolic blood pressure, BMI Body mass index, HDL-C High-density lipoprotein cholesterol, LDL-C Low-density lipoprotein cholesterol

C increased in all models. In Model 3, compared to optimal LDL-C, the odds ratios of hypertension risk were 1.07 (95\% CI, 0.90-1.27) and 1.41 (95\% CI, 1.08-1.84) for near optimal and high LDL-C levels, respectively, in men and 1.18 (95\% CI, 1.03-1.35) and 1.83 (95\% CI, 1.50-2.23) in women. Similar results were obtained in MRA using weighted GRS in model 3, with odds ratios for hypertension risk of 1.08 (95\% CI, 0.91-1.27) and 1.42 (95\% CI, 1.09-1.85) for near optimal and high group LDL-C levels, respectively, in men and 1.18 (95\% CI, $1.03-1.35)$ and 1.84 (95\% CI. 1.51-2.24) in women (Table 5).

\section{Discussion}

In this study, CAVAS was used to recruit men and women aged 40-69years. Of the 19,536 patients analyzed in this study, 11,378 were normal, and 8158 had hypertension. The aim of this study was to demonstrate the causal relationship between LDL-C and hypertension using genetic analysis, and the relationship was confirmed by observational and MRA methods. In the observational study, the relationship between LDL-C and hypertension was not statistically significant; however, MRA showed that the risk of hypertension increased as LDL-C increased in both men and women. The main results of this study confirmed that the relationship between LDL-C and hypertension is influenced by genetic information.

The results from the observational studies and MRA were different in this study. This difference may have been caused by residual confounders not included in the observed regression model [21]. Since there may be an 

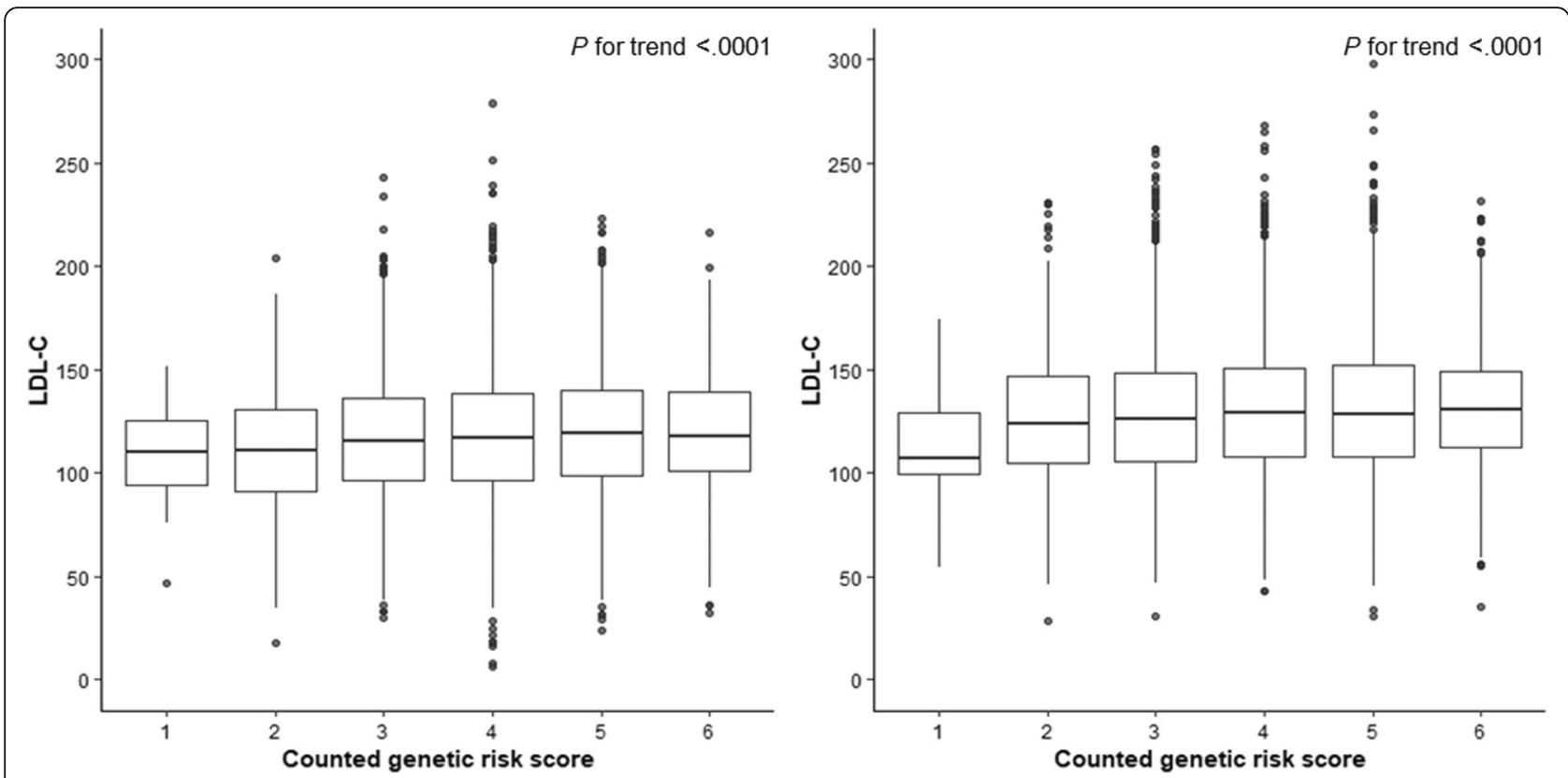

Fig. 2 Association between LDL-C and counted genetic risk scores in men and women. LDL-C low-density lipoprotein cholesterol

inverse relationship between elevated LDL-C in patients with hypertension, a causal relationship was inferred by reducing bias using genetic data.

Cholesterol is generally known as a risk factor for hypertension. However, most studies have only identified a relationship between HDL-C and cardiovascular risk; few have found LDL-C to affect incident hypertension. Otsuka et al. [22] reported the development of hypertension according to LDL-C quintiles. Therein, the risk of hypertension was 1.27 times higher at the highest quintile than the lowest. With the exception of one study conducted in China, the research by Otsuka et al. is the first to demonstrate a longitudinal association between lipid measures and the risk of incident hypertension in Asian individuals, and suggested that dyslipidemia is associated with an increased risk of incident hypertension. As mentioned in their article, the first mechanism potentially explaining the relationship between dyslipidemia and hypertension risk suggests that dyslipidemia impairs endothelial function, which can interfere with nitric oxide production and the control of blood pressure. Second, dyslipidemia can cause development of hypertension by decreasing baroreflex sensitivity. Third, dyslipidemia reduces the distensibility of large elastic arteries, and finally, a lack of physical activity or high-fat diet promotes obesity. In obese individuals, adipose tissue excessively secretes adipocytokines, resulting in insulin resistance and subsequent activation of the sympathetic nervous system and the renin-angiotensin system. These biological changes have been reported to lead to an increase in blood pressure. Our results support this mechanism and hold significance in confirming the causality between LDL-C and hypertension.

However, our study entails some limitations. First, LDL-C was not investigated in CAVAS; therefore, we used the Friedewald formula to calculate LDL-C. Notwithstanding, the National Health Screening Program of Korea also estimates LDL-C using the formula. Second, among the risk factors that could affect hypertension, there were a few that our study could not take into account. Third, generalizing the results of this study to all Koreans would be difficult. However, since the study was conducted using SNPs validated in the literature, we expect that any bias would be minimal. Finally, there is the potential for linkage disequilibrium and pleiotropy as a limitation of MRA [23-25]. Despite these limitations, genetic analysis based on MRA provides a way to overcome the possibility of interpreting causal conclusions in observational studies [26].

In summary, identifying causal relationships in observational studies is not easy. However, Mendelian randomization creates an environment through which causal associations can be identified without performing randomized controlled trials, which are expensive and time-consuming. Using MRA, we found that the relationship between LDL-C and hypertension is indeed causal, and further validation is needed using further next-generation sequencing analysis. 
Table 5 Association between LDL-C and hypertension in observational analysis and Mendelian randomization analysis

\begin{tabular}{|c|c|c|c|}
\hline & Observational analysis & Mendelian rand & \\
\hline & & Counted GRS & Weighted GRS \\
\hline & OR (95\% Cl) & OR (95\% CI) & OR $(95 \% \mathrm{Cl})$ \\
\hline Men & & & \\
\hline Model 1 & & & \\
\hline Optimal & 1.00 (reference) & 1.00 (reference) & 1.00 (reference) \\
\hline Near optimal & $0.84(0.75-0.95)$ & $1.15(0.97-1.37)$ & $1.16(0.97-1.37)$ \\
\hline High & $0.90(0.79-1.01)$ & $1.64(1.25-2.16)$ & $1.65(1.26-2.17)$ \\
\hline Model 2 & & & \\
\hline Optimal & 1.00 (reference) & 1.00 (reference) & 1.00 (reference) \\
\hline Near optimal & $0.91(0.79-1.04)$ & $1.07(0.90-1.26)$ & $1.07(0.90-1.27)$ \\
\hline High & $1.02(0.89-1.17)$ & $1.40(1.07-1.83)$ & $1.41(1.08-1.84)$ \\
\hline Model 3 & & & \\
\hline Optimal & 1.00 (reference) & 1.00 (reference) & 1.00 (reference) \\
\hline Near optimal & $0.92(0.80-1.05)$ & $1.07(0.90-1.27)$ & $1.08(0.91-1.27)$ \\
\hline High & $1.03(0.90-1.18)$ & $1.41(1.08-1.84)$ & $1.42(1.09-1.85)$ \\
\hline Women & & & \\
\hline Model 1 & & & \\
\hline Optimal & 1.00 (reference) & 1.00 (reference) & 1.00 (reference) \\
\hline Near optimal & $0.89(0.79-0.99)$ & $1.18(1.03-1.35)$ & $1.18(1.03-1.36)$ \\
\hline High & $0.89(0.80-0.99)$ & $1.83(1.51-2.23)$ & $1.83(1.50-2.23)$ \\
\hline Model 2 & & & \\
\hline Optimal & 1.00 (reference) & 1.00 (reference) & 1.00 (reference) \\
\hline Near optimal & $0.90(0.79-1.02)$ & $1.18(1.03-1.35)$ & $1.18(1.03-1.36)$ \\
\hline High & $0.92(0.81-1.04)$ & $1.83(1.51-2.23)$ & $1.83(1.50-2.23)$ \\
\hline Model 3 & & & \\
\hline Optimal & 1.00 (reference) & 1.00 (reference) & 1.00 (reference) \\
\hline Near optimal & $0.90(0.79-1.02)$ & $1.18(1.03-1.35)$ & $1.18(1.03-1.35)$ \\
\hline High & $0.92(0.81-1.03)$ & $1.83(1.50-2.23)$ & $1.84(1.51-2.24)$ \\
\hline
\end{tabular}

Model 1: adjusted for age and body mass index

Model 2: Model $1+$ smoking and drinking status

Model 3: Model $2+$ salt intake

LDL-C Low-density lipoprotein cholesterol, GRS Genetic risk score, OR Odds ratio

\section{Conclusions}

In this study, a causal association between LDL-C and hypertension was confirmed using MRA. The causal effects of LDL-C and hypertension were confirmed using genetic information. Our results showed that the relationship between LDL-C and hypertension, which was stronger in women, is reflected in genetic risk scores.

\section{Supplementary Information}

The online version contains supplementary material available at https://doi. org/10.1186/s40885-021-00162-6.

Additional file 1: Supplement Table 1. Associations between genetic polymorphism and LDL-C.

\section{Acknowledgements}

This study was supported by the Korean Society of Hypertension (research number: KSH-P-2017-01) and this research was also supported by funding (code 2004-E71004-00, 2005-E71011-00, 2005-E71013-00, 2006-E71009-00, 2006-E71002-00, 2006-E71011-00, 2007-E71002-00, 2007-E71013-00, 2008E71004-00, 2009-E71006-00, 2010-E71003-00, 2011-E71002-00) from the Korea Centers for Disease Control and Prevention. The Korea Biobank Array (K-CHIP) was designed by Center for Genome Science, Korea National Institute of Health, Korea (4845-301), and related genotyped data were provided by the collaborative Genome Program for Fostering New Post-Genome Industry (3000-3031).

\section{Authors' contributions}

THG analyzed the data and contributed to the writing of the manuscript. KIK and JYJ performed data analysis and interpreted the data. MHY, HSK, JYK, and SBG participated in designing the study. DRK designed the research and contributed to the revision of the manuscript. All authors read and approved the final manuscript 


\section{Funding}

This study was supported by the Korean Society of Hypertension (research number: KSH-P-2017-01)

\section{Availability of data and materials}

The datasets used and/or analyzed during the current study are available from the corresponding author on reasonable request.

\section{Ethics approval and consent to participate}

The study protocol was approved by the Institutional Review Board (IRB) of Wonju Severance Christian Hospital (CR317334).

\section{Consent for publication}

Not applicable.

\section{Competing interests}

The authors declare that they have no competing interests.

\section{Author details}

${ }^{1}$ Center of Biomedical Data Science, Yonsei University Wonju College of Medicine, Wonju, Republic of Korea. ${ }^{2}$ Department of Biostatistics, Yonsei University Wonju College of Medicine, Wonju, Republic of Korea. ${ }^{3}$ Center of Cancer Data, National Cancer Center, Ilsan, Republic of Korea. ${ }^{4}$ SENTINEL Team, Division of Endocrinology, Department of Internal Medicine, Yonsei University College of Medicine, Seoul, Republic of Korea. ${ }^{5}$ Artificial Intelligence BigData Medical Center, Yonsei University Wonju College of Medicine, Wonju, Republic of Korea. ${ }^{6}$ Department of Cardiology, Yonsei University Wonju College of Medicine, Wonju, Republic of Korea. ${ }^{7}$ Institute of Genomic Cohort, University Wonju College of Medicine, Wonju, Republic of Korea. ${ }^{8}$ Department of Preventive Medicine, Yonsei University Wonju College of Medicine, Wonju, Republic of Korea. ${ }^{9}$ Department of Precision Medicine, Yonsei University Wonju College of Medicine, 20 Ilsan-ro, Wonju-si, Gangwon-do 26426 Wonju, Republic of Korea.

Received: 12 May 2020 Accepted: 8 January 2021

Published online: 26 February 2021

\section{References}

1. Whelton PK. Epidemiology of hypertension. Lancet. 1994;344:101-6.

2. Lim SS, Vos T, Flaxman AD, Danaei G, Shibuya K, Adair-Rohani H, et al. A comparative risk assessment of burden of disease and injury attributable to 67 risk factors and risk factor clusters in 21 regions, 1990-2010: a systematic analysis for the global burden of disease study 2010. Lancet. 2012;380:222460 .

3. Lozano R, Naghavi M, Foreman K, Lim S, Shibuya K, Aboyans V, et al. Global and regional mortality from 235 causes of death for 20 age groups in 1990 and 2010: a systematic analysis for the global burden of disease study 2010. Lancet. 2012;380:2095-128.

4. Han S, Moon S, Kim YJ, Kim BJ. The introduction of disease genomic database for clinical practice. Public Health Wkly Rep. 2017;10:82-6.

5. Lee KL. Study on community services for hypertension patients and families [Master's thesis]. Yongin, Korea: Kangnam University; 2001.

6. Kim H, Son H. Prevalence of hypertension and its risk factors among aged 65 and over in Korea. J Korean Biol Nurs Sci. 2012;14:282-90.

7. Emdin CA, Khera AV, Kathiresan S. Mendelian randomization. JAMA. 2017; 318:1925-6.

8. Smith GD, Ebrahim S. 'Mendelian randomization': can genetic epidemiology contribute to understanding environmental determinants of disease? Int J Epidemiol. 2003:32:1-22.

9. Lawlor DA, Harbord RM, Sterne JA, Timpson N, Davey SG. Mendelian randomization: using genes as instruments for making causal inferences in epidemiology. Stat Med. 2008;27:1133-63.

10. Zheng J, Baird D, Borges MC, Bowden J, Hemani G, Haycock P, et al. Recent developments in Mendelian randomization studies. Curr Epidemiol Rep. 2017:4:330-45.

11. Sacks FM, Pfeffer MA, Moye LA, Rouleau JL, Rutherford JD, Cole TG, et al. The effect of pravastatin on coronary events after myocardial infarction in patients with average cholesterol levels. Cholesterol and recurrent events trial investigators. N Engl J Med. 1996;335:1001-9.

12. Baigent C, Keech A, Kearney PM, Blackwell L, Buck G, Pollicino C, et al. Efficacy and safety of cholesterol-lowering treatment: prospective meta- analysis of data from 90,056 participants in 14 randomised trials of statins. Lancet. 2005;366:1267-78.

13. The lipid research clinics coronary primary prevention trial results. I. Reduction in incidence of coronary heart disease. JAMA. 1984;251:351-64.

14. Sever PS, Dahlof B, Poulter NR, Wedel H, Beevers G, Caulfield M, et al. Prevention of coronary and stroke events with atorvastatin in hypertensive patients who have average or lower-than-average cholesterol concentrations, in the Anglo-Scandinavian cardiac outcomes trial--lipid lowering arm (ASCOT-LLA): a multicentre randomised controlled trial. Lancet. 2003;361:1149-58.

15. Shepherd J, Cobbe SM, Ford I, Isles CG, Lorimer AR, MacFarlane PW, et al. Prevention of coronary heart disease with pravastatin in men with hypercholesterolemia. West of Scotland coronary prevention study group. N Engl J Med. 1995;333:1301-7.

16. Downs JR, Clearfield M, Weis S, Whitney E, Shapiro DR, Beere PA, et al. Primary prevention of acute coronary events with lovastatin in men and women with average cholesterol levels: results of AFCAPS/TexCAPS. Air force/Texas coronary atherosclerosis prevention study. JAMA. 1998;279: $1615-22$.

17. Randomised trial of cholesterol lowering in 4444 patients with coronary heart disease: the Scandinavian simvastatin survival study (4S). Lancet. 1994; 344:1383-9.

18. Friedewald WT, Levy RI, Fredrickson DS. Estimation of the concentration of low-density lipoprotein cholesterol in plasma, without use of the preparative ultracentrifuge. Clin Chem. 1972;18:499-502.

19. Moon S, Kim YJ, Han S, Hwang MY, Shin DM, Park MY, et al. The Korea biobank array: design and identification of coding variants associated with blood biochemical traits. Sci Rep. 2019;9:1382.

20. Lee H-Y, Shin J, Kim G-H, Park S, Ihm S-H, Kim HC, et al. 2018 Korean Society of Hypertension Guidelines for the management of hypertension: part IIdiagnosis and treatment of hypertension. Clinical Hypertension. 2019;25:20.

21. Bakian AV, Huber RS, Coon H, Gray D, Wilson P, McMahon WM, et al. Acute air pollution exposure and risk of suicide completion. Am J Epidemiol. 2015; 181:295-303.

22. Otsuka T, Takada H, Nishiyama Y, Kodani E, Saiki Y, Kato K, et al. Dyslipidemia and the risk of developing hypertension in a working-age male population. J Am Heart Assoc. 2016;5:e003053.

23. Burgess S, Butterworth A, Thompson SG. Mendelian randomization analysis with multiple genetic variants using summarized data. Genet Epidemiol. 2013;37:658-65

24. Sekula P, Del Greco MF, Pattaro C, Kottgen A. Mendelian randomization as an approach to assess causality using observational data. J Am Soc Nephrol. 2016;27:3253-65.

25. Davey Smith G, Hemani G. Mendelian randomization: genetic anchors for causal inference in epidemiological studies. Hum Mol Genet. 2014;23:R8998.

26. Winslow UC, Rode L, Nordestgaard BG. High tobacco consumption lowers body weight: a Mendelian randomization study of the Copenhagen general population study. Int J Epidemiol. 2015;44:540-50.

\section{Publisher's Note}

Springer Nature remains neutral with regard to jurisdictional claims in published maps and institutional affiliations.

Ready to submit your research? Choose BMC and benefit from:

- fast, convenient online submission

- thorough peer review by experienced researchers in your field

- rapid publication on acceptance

- support for research data, including large and complex data types

- gold Open Access which fosters wider collaboration and increased citations

- maximum visibility for your research: over $100 \mathrm{M}$ website views per year

At $\mathrm{BMC}$, research is always in progress.

Learn more biomedcentral.com/submissions 